\title{
La nueva sociedad de frontera. \\ Los grupos sociales en la frontera de San Ignacio de Ledesma, Chaco occidental, finales del siglo XVIII
}

\author{
Enrique Normando Cruz \\ Centro de Estudios Indígenas y Coloniales, \\ Universidad Nacional de Jujuy
}

\begin{abstract}
Caracterizada como una frontera de guerra o de un refugio de asociales, presidiarios y forajidos, la frontera chaquense que corresponde a las ciudades meridionales de Jujuy y Salta, se conoce como frontera de San Ignacio de Ledesma por hallarse ubicada alli la importante Reducción de San Ignacio y el fuerte presidio de Nuestra Señora del Rosario de Ledesma. En el trabajo se analizan los grupos y las relaciones sociales que se desenvolvieron alrededor de los fuertes-presidios que guarnecían y colonizaban esta región, a partir de la numerosa correspondencia que sostuvieron las autoridades capitulares y de la intendencia de Salta del Tucumán con los hacendados y comandantes de los presidios. Dando lugar a un panorama que reconsidera algunas de las conclusiones elaboradas sobre los grupos y sus relaciones sociales y económicas en las áreas fronterizas periféricas de Hispanoamérica.
\end{abstract}

\begin{abstract}
Dedicado a Carlos Tolaba, desertor, Rufina su mujer, fugada de la familia (ambos fieles al amor). A los sueños de Antonio Tabarcachi, jefe toba y sacristán de reducción.

"Las relaciones entre el beduino y el sedentario no se presentan solamente bajo el aspecto de un continuo conflicto. el beduino es frecuentemente llamado a la casa que codicia. El nómada, hasta entonces vencedor, es puesto fuera de combate por la pólvora del cañón”. ${ }^{1}$
\end{abstract}

\section{Introducción}

Caracterizada como una frontera de guerra, ${ }^{2}$ presidiaria o refugio de asociales y forajidos, la frontera chaquense de las ciudades Meridionales de Jujuy y Salta se conoce como frontera de San Ignacio de Ledesma por hallarse ubicada allí la reducción de San Ignacio y el fuerte presidio de Nuestra Señora del Rosario de Ledesma. En un momento en que han finalizado los

1 Braudel, Fernand, El Mediterráneo y el mundo mediterráneo en la época de Felipe II, tomo I, México, 1992, págs. 236-238.

2 Garavaglia, Juan Carlos, "La guerra en el Tucumán colonial: sociedad y economía en un área de frontera (1660-1760)", Revista Latinoamericana de Historia Económica y Social HISLA, IV, Lima, 2. ${ }^{\circ}$ semestre 1984, págs. 21-34. 
procesos de las etapas "defensivas" y de la "guerra ofensiva" contra las poblaciones chaquenses; ${ }^{3}$ la expulsión y reestructuración de las misiones jesuíticas en manos franciscanas y, el cambio de las políticas estatales hacia el Chaco occidental desde la gobernación de Gregorio de Matorras en adelante. Los últimos años del siglo XVIII cristalizan todos estos procesos en un nuevo tipo de "sociedad de frontera".

Este artículo describe y analiza los grupos y las relaciones sociales que se dan alrededor de los fuertes-presidios de la región, especialmente las que se desarrollan en el de Nuestra Señora del Rosario de Ledesma, sede de la comandancia general de fronteras y alrededor del cual vemos jugar, en las florecientes haciendas azucareras y las importantes reducciones de San Ignacio de Ledesma y de Nuestra Señora de las Angustias de Centa, a las distintas políticas oficiales, las consiguientes respuestas y acciones de los indígenas chaquenses y el accionar de los hacendados, misioneros y comerciantes.

La documentación principal proviene de la numerosa correspondencia que entabló el comandante general de la frontera con sus superiores de la ciudad de Jujuy y de la intendencia de Salta, entre los años 1790-1800, además de la correspondencia particular que los hacendados tienen con sus mayordomos, toda ella depositada en el Archivo Histórico Provincial. Además el panorama se completó con numerosos inventarios de bienes y expedientes judiciales de los archivos de tribunales, de la curia eclesiástica; y las crónicas de misioneros y colonizadores que recorren la región en la segunda mitad del XVIII. Por último también se tuvo en cuenta la importante producción bibliográfica de los últimos años que explica, en su dinámica particular y en sus relaciones con las ciudades hispanocoloniales, esta porción tan importante para el tráfico mercantil regional de las tierras bajas chaquenses. ${ }^{4}$

3 Vitar, Beatríz, Guerra y misiones en la frontera chaqueña del Tucumán (1700-1767), Madrid, 1997.

4 Deben ser mencionados aquí los trabajos de Doucet, Gastón, "Sobre cautivos de guerra y esclavos indios en el Tucumán. Notas en torno a un fichero documental salteño del siglo XVIII", Revista de Historia del Derecho, 16, Buenos Aires, 1988; Garavaglia, Juan Carlos, "La guerra en el Tucumán colonial...”; Santamaría Daniel y Peire Jaime, “Guerra o comercio pacífico? La problemática interétnica del Chaco centro-occidental del siglo XVIII," Anuario de Estudios Americanos, L-2, Sevilla, 1993; Santamaría Daniel, "Población y economía interna de las poblaciones aborígenes del chaco en el siglo XVIII," ANDES, 9, Salta, 1998; Santamaría, Daniel, "Paz y asistencialismo vs. guerra y esclavitud. La política reformista del gobernador Gerónimo de Matorras en el Chaco CentroOccidental, 1769-1775," Folia Histórica del Nordeste, Resistencia, 1999 [en prensa]; Teruel, Ana, "Zenta y San Ignacio de los Tobas. El trabajo en dos misiones del Chaco occidental a fines de la colonia." Anuario del IEHS, 9, Tandil, 1994 y Vitar, Beatríz, "Las fronteras bárbaras en los virreinatos de Nueva España y Perú (Las tierras del norte de México y oriente del Tucumán en el siglo XVIII)", Revista de Indias, Madrid, 1995. 


\section{Los fuertes de la frontera de Jujuy en la última década del XVIII}

La frontera chaquense occidental de la jurisdicción de Jujuy que protegía a las ciudades de Jujuy y Salta, estaba constituida a finales del siglo XVIII por la siguiente serie de fuertes de oeste a este: El Pongo, Río Negro, Ledesma, San Bernardo y Santa Bárbara. Durante la última década del XVIII quedan únicamente en pie: San Bernardo, Santa Bárbara y Ledesma, como resultado de la ampliación y consolidación de la frontera a partir de la fundación de la reducción de Nuestra Señora de las Angustias de Centa (1779) y de la ciudad de San Ramón Nonato de La Nueva Orán (1794); que inutiliza a los otros fuertes y los convierte en unidades productivas, integrándolos al sistema hacendístico regional. En este proceso el fuertepresidio de Ledesma reemplazará al de Río Negro como cabeza de la comandancia general de fronteras, pudiéndose apreciar con el cambio del asiento y con la desaparición de los establecimientos mencionados, la consolidación colonizadora de esta frontera y el carácter lineal - aunque no exento de retrocesos- del proceso de pasaje de fuerte a hacienda, que se vive a nivel regional.

Esto le sucederá a la mayor parte de los establecimientos mencionados, así el fuerte de El Pongo que erigido en 1690 por el cabildo de la ciudad de Jujuy, y constituido en lo que queda del XVII y primera mitad del XVIII en un auténtico baluarte en la protección a las entradas de indios del Chaco; además de servir de punto de partida a varias campañas de caza de piezas al Chaco en la llamada "guerra del Pongo" del año 1706; para 1786 ya no mostrará huellas militares, sino únicamente económicas, pues en su lugar una importante hacienda va a producir melaza y chancaca de caña de azúcar y cereales para el abastecimiento de la ciudad.

Lo mismo sucede con el fuerte de Río Negro, que fundado en 1749 por orden del gobernador Martínez del Tineo como Nuestra Señora de los Dolores de Río Negro o fuerte de Lavayén - como también se lo conoce-, constituye un importante eslabón en la política de campañas militares de este gobernador. Pero luego, en 1788, sólo dos años después que el anterior caso, el fuerte de Río Negro dará lugar a la hacienda homónima; y en sus tierras se producirán panes de azúcar procesados en trapiches muleros, y aguardiente hecho en alambiques construidos en los propios talleres de la hacienda. Siendo que la ahora hacienda de Río Negro tiene además la particularidad de contar con la mayor cantidad de esclavos para esta porción 
fronteriza del Chaco: dieciséis, todos ellos especializados en distintos oficios de la producción de azúcar y aguardiente. ${ }^{5}$

En tercer lugar tenemos el caso del fuerte de Santa Bárbara, que altera un tanto el orden de transformación del fuerte en hacienda, pero que finaliza como los anteriores constituyéndose también en unidad productiva. Santa Bárbara fue erigida como hacienda en 1765 en tierras dadas por merced por el gobernador Juan Manuel Fernández Campero, al teniente de gobernador de la ciudad de Jujuy, Diego Tomás Martínez de Iriarte en 1755. En un momento de plenas campañas militares, la única forma que encuentra Diego Tomás para asegurar su propiedad es construir un fuerte, el que a su muerte a mediados de 1770 dejará a su viuda, doña Paula Fernández Córdoba, que explotará sus tierras y ganado como si fuera una hacienda de su propiedad, con el auxilio del comandante del fuerte-hacienda, José Gil. Luego, en 1779 al morir también ella, la testamentaría la llevará adelante el comandante Gil, va a entregar las tierras, sementeras y ganado del antiguo fuerte-hacienda, como hacienda únicamente de Santa Bárbara, a los hijos del fallecido matrimonio Martínez de Iriarte. ${ }^{6}$

Por último tenemos el caso del fuerte-presidio de Ledesma, el pasaje descrito también habría de llevarse adelante pero ya en el período independiente, pues en las tierras, ganados y mano de obra del antiguo fuerte se construirá cerca de 1830 la importante hacienda de Ledesma productora de ganado vacuno, mular y de azúcar, bajo la propiedad de su antiguo comandante militar don Carlos Sevilla.?

\section{El fuerte de Ledesma en la frontera chaquense}

El fuerte-presidio de Ledesma es heredero de una vieja tradición de presencia hispánica conquistadora y colonizadora en esta porción del Chaco occidental y remonta su origen a distintos emprendimientos en la

5 Ambas haciendas son propiedad de Gregorio de Zegada, comandante general de fronteras de Jujuy. Archivo del Obispado de Jujuy (en adelante AOJ), Testamento e inventario de bienes de Gregorio de Zegada, Jujuy, 29 de julio de 1794, 8, 1.

6 Archivo de Tribunales de Jujuy (en adelante ATJ), Testamento e inventario de bienes de Paula Fernández Córdoba, Jujuy, 1779, 53-1726.

7 Cruz, Enrique, "Fuertes y presidios en el pedemonte jujeño. Finales del siglo XVIII", Actas del XIX Encuentro de Geohistoria Regional, Corrientes, 1999. 
región. Por un lado el fracasado asentamiento de Santiago de Guadalcázar, ciudad fundada en 1628 y que sobrevive hasta 1635 y por otro lado, a los fuertes fundados como apoyo a las campañas misioneras y entradas militares del siglo XVII y primera mitad del XVIII. De efímera existencia los fuertes de San Francisco, mencionado por el misionero Lozano en la descripción de la entrada de 1671, y San Rafael, fundado por los soldados que acompañaban al misionero y antiguo encomendero Pedro Ortíz de Zárate en la entrada que hace a sus mercedes de tierras en 1682; serían los antecedentes históricos del de Ledesma.

Este fuerte-presidio fue fundado con el nombre de Nuestra Señora del Rosario, entre 1682 y 1711, con el objetivo de guardar al pueblo de San Antonio de indios ojotaes. ${ }^{8}$ Erigido por el teniente de gobernador de Jujuy Antonio de la Tijera, será fundamental para el desarrollo de las entradas militares de caza de piezas, ${ }^{9}$ para las fundaciones colonizadoras de la región desde 1710 en adelante, ${ }^{10}$ y para la salvaguarda de las reducciones jesuíticas y franciscanas de San Ignacio y de Centa.

Por otro lado, en la región de estudio y durante la última década del XVIII, se termina de articular el comercio mercantil entre las ciudades de Jujuy y Salta con las de Orán, Tarija y Santa Cruz de la Sierra, lo que dará lugar a un mercado ampliado que incluye a la frontera chaquense de las jurisdicciones de Jujuy y Salta. En este nuevo escenario, el fuerte de Ledesma, y los fuertes-hacienda de Río Negro y Santa Bárbara, ${ }^{11}$ jugarán un importante rol en el reclutamiento, control y regulación de la población indígena y mestiza que trabaja en y para las haciendas y reducciones franciscanas; y del mismo modo, serán muy útiles para el mantenimiento expedito y rentable de la carrera de los comerciantes y traficantes de la región, cumpliendo además con el objetivo político de posibilitar la colonización estatal y la evangelización religiosa.

8 Morillo, Francisco fray (1780) Diario del viaje al río Bermejo, En Angelis, Pedro de, Entradas al Chaco, Colección de obras y documentos relativos a la historia antigua y moderna de las provincias del Río de la Plata, Buenos Aires, 1910.

9 Así se llamaba a los niños, mujeres y jóvenes adultos chaquenses, que tomados como prisioneros por las partidas militares de las ciudades del Tucumán colonial, terminaban repartidos para el servicio doméstico de la ciudad, el trabajo en las haciendas, o conducidos a las ciudades mercantiles del sur del Charcas (ATJ, Recibo de 15 piezas entregadas por Diego Tomás Martínez de Iriarte, Jujuy, $1745,38,1264)$. pág. 374.

10 Lozano, Pedro, Descripción Corográfica del Gran Chaco Gualamba, Tucumán, 1941,

11 Archivo Histórico de Jujuy (en adelante AHJ), Archivo Ricardo Rojas (en adelante ARR), Correspondencia entre Carlos Sevilla y Gregorio de Zegada, Jujuy, 1780-1800, 45, 449 y 453. 


\section{Los grupos sociales y la vida de frontera}

Cuando se describe a esta porción del Chaco durante el siglo XVIII, se destaca que el proceso de conquista que va de 1700 a 1767, dejó como saldo una frontera militar, presidiaria y multiétnica, y que tales características se prolongan para todo lo que resta del siglo, hasta en la centuria siguiente. ${ }^{12}$ Sin embargo, la expulsión de los jesuitas de sus misiones, que libera tierras y mano de obra para los hacendados y colonos, tanto como los cambios en las políticas estatales hacia el Chaco, del gobernador Gregorio de Matorras a García Pizarro, dará lugar en la frontera a una configuración social y económica que si bien mantiene algunos de los rasgos básicos conformados en los primeros cincuenta años del siglo XVIII, altera otros. Se presenta así un nuevo tipo de frontera, más variopinta que la monocroma caracterización que se hace de una frontera militar y presidiaria, a la par que se debe replantear la mirada de ciertas conductas entre las relaciones interétnicas de los grupos indígenas.

\section{Los presidiarios de la frontera}

Regresando a la idea anterior, el fuerte en la frontera tucumana del Chaco ha sido considerado por gran parte de la historiografía misionera como el lugar de descarga de la gente perdida. ${ }^{13}$ Juicio que se encuentra también en parte de la historiografía, que considera a esta porción de la frontera chaquense y a sus fuertes como el destino y refugio de los asociales: $;{ }^{14}$ entendiendo que estos individuos que "inundaban" las ciudades, los montes y la campaña, serían los segregados de una estructura social estamentada y rígida que no contemplaba ningún tipo de movilidad social. Pero al mercantilizarse la ciudad de Jujuy a partir de 1690, incluirá en ese proceso a su frontera con el Chaco, que con la efectivización de las mercedes de tierras en la construcción de haciendas productoras de ganado, azúcar y aguardiente; más el desarrollo económico de las reducciones, se incorporará con vigor en la floreciente estructura mercantilista regional.

Algunos de los rasgos de esta frontera chaquense como porción del Chaco occidental, es que alberga a miles de cabezas de ganado vacuno y

12 Vitar, Beatriz, Guerra y misiones...., págs. 109 y 110.

13 Lozano, Pedro, Descripción Corográfica...., pág. 414.

14 Acevedo, Edberto Oscar, La intendencia de Salta de Tucumán en el virreinato del Río de la Plata, Mendoza, 1965, pág. 347. 
otros miles de mulas, además de producir 20.000 pesos de utilidad a los hacendados productores de azúcar y aguardiente. En cuanto a su población, está habitada por varios cientos de mestizos y algunos españoles, unas cuantas decenas de negros esclavos y pardos libres, y entre siete ${ }^{15}$ a cuarenta mil indios de las etnias toba, mocovíes y wichís. ${ }^{16}$

Esta nueva configuración social nos está mostrando una nueva frontera, que obliga a reexaminar la categoría del presidiario, pues ya no se estaría hablando de una sociedad estamental, de encomenderos, siervos y gente desviada, perdida o asocial; sino de una sociedad con estamentos menos rígidos, casi fracturados por el desarrollo económico mercantil que ahora no excluye la movilidad social. La cual estaría conformada por mercaderes; encomenderos notablemente empobrecidos y trabajadores de diversos grupos étnicos, englobados en la denominación de "plebeyos", quienes según sus intereses vagabundean, sirven o trabajan para los dos primeros grupos; y cuando se resisten a hacerlo o no es conveniente su holgazanería para la estructura productiva, terminan siendo reducidos como presidiarios o peones en algún fuerte o hacienda de la frontera.

Respecto de quienes son estos individuos tenemos que los presidiarios que recibe el fuerte presidio de Ledesma provienen principalmente de las ciudades de Salta y Jujuy y de los curatos de Humahuaca o Cochinoca; incluso llega uno proveniente de un presidio de Buenos Aires. A su vez, desde el mismo presidio de Ledesma se remiten presos a otros fuertes de los alrededores, como San Bernardo o Balbuena, en la porción salteña y tucumana de la frontera chaquense, y hasta se llega a mandar un preso a un fuerte presidio llamado de "Valdivia", fuera de la jurisdicción.

Junto a este traslado, desde las ciudades y entre los fuertes de la frontera, los presos suelen ser requeridos también desde la ciudad de Jujuy por las autoridades capitulares para distintas tareas: construir la cárcel, trabajar en las obras públicas, o arreglar las acequias. Su remisión se hace en pequeños grupos de dos o tres presos custodiados por igual número de soldados. ${ }^{17}$

15 Matorras, Gerónimo de, Diario de la expedición hecha en 1774 a los países del gran Chaco desde el fuerte del Valle por el gobernador del Tucumán. En Angelis, Pedro de, Entradas al Chaco, Colección de obras y documentos relativos a la historia antigua y moderna de las provincias del Río de la Plata, Jujuy, 1989, págs. 22-30.

16 Jolís, José, Ensayo sobre la Historia Natural del Gran Chaco, Resistencia, 1972, pág. 254.

17 "Va el cabo Rodo con dos soldados a conducir unos presos que me dijo enviara el señor alcalde para arreglar la cárcel". Más adelante en otra carta del comandante del fuerte se aclara que son cuatro los presidiarios remitidos por orden del alcalde Bentura Marquiegui (AHJ, ARR, Correspondencia entre Carlos Sevilla y Gregorio de Zegada, Jujuy, 1780-1800, 435 y 479). 
Estos presidiarios se dirigen a servir como soldados en el fuerte de Ledesma en cumplimiento de condenas que corresponden a penas directas para varios delitos, o como accesoria de otros, o como solución final para los reincidentes.

Por ejemplo la pena para el abigeato era de cien azotes y el servicio fronterizo de unos cuantos meses a ración y sin sueldo, de acuerdo a la cantidad y calidad del ganado robado. En el caso de juego de cartas o dados, las penas eran pecuniarias, contemplándose la prisión en el fuerte sólo en caso de reincidencia y únicamente para las indios, negros esclavos o pardos. Para el vagabundeo u holgazanería y la portación de armas, el castigo principal era de cincuenta a doscientos azotes y unos meses de prisión. Por último, el "arrime" a una estancia ${ }^{18}$ de los vagabundos o forasteros, las heridas con arma blanca, el galope en las calles de la ciudad, el consentimiento de borracheras por parte de los pulperos y la falta de pago de deudas, podían conducir al servicio fronterizo en un fuerte. ${ }^{19}$ Siendo tantas las conductas que pueden merecer prisión en la frontera, es seguro que las prisiones no son suficientes y que los fuertes estarían saturados de criminales y delincuentes. Sin embargo, ese no es el panorama y son relativamente pocos quienes terminan finalmente condenados y traslados para cumplir el servicio en el más reconocido fuerte-presidio de la región, el fuerte de Ledesma.

Entre ellos contamos un indio tupí de los "reinos de Portugal" que por robo reiterado de una mujer casada recibe la condena de servir seis meses en el fuerte. A Juan Costa, indio alcalde de Purmamarca se lo destierra a Ledesma por matar a un indio de su pueblo estando "privado" por el alcohol. Diego de los Reyes, mestizo, por robar catorce mulas con dos madrinas, recibe la condena de cien azotes al voleo en la plaza pública y seis meses de destierro a ración y sin sueldo. También hay un delincuente anónimo en el registro, cuyo delito de latrocinio recibe la condena de tres meses de presidio. Todos son condenados entre 1730 y 1790 . A ellos se suman seis presos que llegan al fuerte de Ledesma en marzo de 1790, de

18 Se llamaba "arrime" a la costumbre prohibida por las autoridades de amparar dentro del casco exterior de una hacienda a individuos con sus familias, quienes eran conchabados estacionalmente por los hacendados dejándolos librados a sus propios medios cuando no se los requería para el trabajo. En este espacio muchos individuos roban ganado de la hacienda o de las haciendas vecinas y asaltaban las arrías de mulas y vacas.

19 Cruz, Enrique, "Vagabundos, malentretenidos y holgazanes. Control y descontrol en los sectores sociales "plebeios" del pedemonte Surandino, Jujuy, siglo XVIII," Informe de avance, Beca de iniciación del CONICET, Jujuy, 1999. 
los cuales sólo dos quedan en él y los cuatro restantes marchan para el fuerte que resguarda a la reducción de Centa. Entre este grupo de seis presidiarios queda uno llamado Pedro Pablo Salguero y un peón Julián Ortíz, que no pasan a servir como presidiarios sino que entran a trabajar directamente como peones en la hacienda del comandante general de armas de la ciudad de Jujuy, Gregorio de Zegada, ${ }^{20}$ además comandante general de fronteras de la región. El 26 de enero de 1792 el alcalde Ventura Marquiegui (el mismo que solicita presos para terminar con la cárcel) pide el envío de cuatro soldados para trasladar a cuatro presos a la frontera y repartirlos entre los fuertes, sin mencionar la causa de la condena.

En promedio es probable que el fuerte de Ledesma contara en los últimos años del XVIII con el servicio de tres o cuatro presos, y una cantidad similar o menor en los fuertes de San Bernardo y Santa Bárbara. Para una frontera que entre 1780-1790 tiene el servicio regular de 50 partidarios, repartidos de la siguiente manera: 27 a 30 soldados en el fuerte de Ledesma, 9 en Santa Bárbara y 11 en San Bernardo, ${ }^{21}$ resulta que el peso de los presidiarios es muy bajo, y la calificación de "frontera presidiaria" resulta ahora un tanto exagerada, por lo menos para esta porción del Chaco occidental.

Además de esta breve consideración cuantitativa, surge el problema de la calidad de lo sujetos remitidos a servir en Ledesma. Entre los presidiarios puede haber abigeos, ladrones, homicidas culposos y secuestradores de mujeres, junto con peones, esclavos cimarrones, vagabundos u holgazanes. Siendo probable que los abigeos y vagabundos hayan sido en realidad "arrimantes" de una hacienda, con el consentimiento del hacendado, que los necesita para trabajar cierto tiempo; y que en el período de desocupación, este peón de hacienda alimentaría a su familia con el ganado que robaba. También una deuda impagada puede resultar en una situación similar y la solución que encuentra el hacendado, que por lo general tiene algún puesto militar en la comandancia de la frontera, es mandarlo a trabajar en sus haciendas del Chaco.

Sintetizando, los presos que encontramos sirviendo a finales del XVIII en los fuertes de esta frontera chaquense están un poco lejos de las categoría de "asóciales y perdidos" con que la denuncia eclesiástica y esta-

20 AHJ, ARR, Correspondencia entre Carlos Sevilla y Gregorio de Zegada, Jujuy, 1780-1800, 478 у 480.

21 AHJ, ARR, Lista general de la tropa partidaria y pago de la frontera de Río Negro, Jujuy, $1790,43,2$. 
tal los caracteriza. Constituyendo un nuevo tipo de presidiario que surge de diversas razones: la inexistencia de un mercado laboral en la estructura económica mercantilista de la región, la renuencia de vagabundos, holgazanes y "malentretenidos" por pasar a conformar un mercado laboral que los obligaría a abandonar el control de algunos de los medios de producción que detentan, y por último, la connivencia de los hacendados, que encuentran muy útil emplearlos únicamente en épocas de mayor demanda de trabajo, dejándolos librados a que encuentren solos las soluciones para la reproducción social de su grupo. Grupo social que es tolerado por lo conveniente que resulta para una economía precapitalista que carece de un mercado laboral, pero a la vez controlado cuando perturban demasiado el orden o saturan la ciudad mediante el aprisionamiento en un fuerte.

Esta difícil identificación social y laboral de los presidiarios llena de inquietudes sobre todo a las autoridades civiles, principalmente por los problemas que suceden cuando tienen que realizar la remisión, traslado y control hacia y desde los fuertes. Así lo expresa el sargento Lorenzo Revuelta, a cargo del fuerte de Ledesma por viaje del comandante Carlos Sevilla a la ciudad de Salta: en una carta al comandante general Gregorio de Zegada acusa recibo de seis presos mandados desde la ciudad de Jujuy, sujetos con prisiones y custodiados por seis soldados. Según la orden de la comandancia general de la frontera, cuatro de ellos debían continuar hacia el fuerte que protege la reducción de Centa, quedando dos en Ledesma, lo que ejecuta el sargento inmediatamente. Pero, para su desazón, ve regresar a los cuatro milicianos que mandó a realizar el traslado, con las prisiones entre las manos y la noticia de que tres de los presos se fugaron y sólo pudieron hacer llegar a su destino a uno de ellos.

Con una antigüedad de servicio de más de diez años al comando de un fuerte (ya que había sido su comandante antes de la llegada de Carlos Sevilla), y a cargo de comandar las campañas de salida de escarmiento y recogida de los indios fugados o agresores de las misiones de la región, el experimentado sargento Lorenzo Revuelta entiende que la fuga no se debe a la ineptitud de sus hombres, sino que resulta de la velada complicidad que a veces existe entre milicianos y presidiarios. Por eso expresa a sus superiores, con cierta resignación, que las emboscadas y partidas organizadas para atrapar a los fugados en las puertas de salida del Chaco hacia los pueblos andinos de la Quebrada de Humahuaca, por más que los encuentre "no los traerán". Por lo que decide ir a buscarlos personalmente, aunque tampoco tendrá éxito y sólo le quedará comunicar a las autoridades que estén 
pendientes de la aparición de los prófugos en los pueblos de indios de Tilcara o Humahuaca. ${ }^{22}$

Sin embargo el mayor peligro no es la fuga sino que esta complicidad puede llegar a convertirse en alianza, como sucede en 1781-1782, cuando en una de las repercusiones regionales al alzamiento de Túpac Amaru, los soldados de Ledesma no se oponen demasiado al alzamiento toba de la misión de San Ignacio, y hasta un soldado partidario, Carlos Quiroga lidera a los mestizos y criollos que junto a los tobas mencionados toman el fuerte de Ledesma, con lo que llenan de pánico a las autoridades de la región que ven confirmados sus peores temores. Finalmente el alzamiento se lograra sofocar, luego de cuatro meses de campañas y de un duro escarmiento a los rebeldes y a los fugados de las reducciones. ${ }^{23}$

De todas maneras, entre soldados y presidarios no hay demasiadas diferencias: muchos de los milicianos que se alistan en el fuerte compartieron con los presos el espacio laboral de la ciudad, o sirvieron juntos como peones en las haciendas de los comandantes de los fuertes de la frontera que cuando no pueden hacer cumplir una deuda los remiten a un fuerte a ocupar las plazas vacantes para cobrarse la deuda de su soldada. Tal vez la única diferencia entre ellos, es que el preso no cobra o cobra sólo una parte de la paga por el servicio en el fuerte, el trabajo en sus tierras o en las sementeras de la hacienda de la autoridad, y con el resto o la totalidad de la soldada se paga su deuda. El soldado, en cambio recibe el total del pago por un servicio realizado en el mismo espacio laboral que el anterior, trabajando codo a codo con quienes tiene que custodiar.

\section{Los soldados partidarios de la frontera}

En 1790 hay 21 soldados en el fuerte de Ledesma, dirigidos por un comandante, un segundo de comandante, un teniente, un capitán, un alférez, cuatro cabos y un armero. Estos partidarios que parecen haber entablado cierta alianza tácita con los presidiarios, además de tener en común con ellos una "vida licenciosa" ${ }^{24}$ presentan otras características. En primer

\footnotetext{
446 y 466 .

22 AHJ, ARR, Correspondencia entre Carlos Sevilla y Gregorio de Zegada, Jujuy, 1780-1800, 361 y 479 .

23 AHJ, ARR, Correspondencia entre Carlos Sevilla y Gregorio de Zegada, Jujuy, 1780-1800,

24 Lozano, Pedro, Descripción Corográfica...., pág. 414.
} 
lugar una gran libertad de movilidad espacial, pues además de los movimientos de tropas que las autoridades del fuerte y de la ciudad disponen para diversos asuntos, como reforzar algún establecimiento en peligro real o potencial de ataques indígenas, o para prestar un servicio específico, como reparar la capilla de una reducción o fuerte o construir la cárcel de la ciudad; los soldados se movilizan con cierta libertad entre uno y otro fuerte de la frontera.

Así tenemos soldados que huyen del fuerte de Santa Bárbara hacia el de Ledesma porque no "les gusta" el trato que les da su comandante; o que se fugan del fuerte que defiende la misión de Centa, y que marchan al de Santa Bárbara sin especificarse las causas. Deserciones y fugas que las autoridades solamente comunican a sus superiores aceptándolas de hecho, sin tomar medidas, tal vez por la limitada cantidad de efectivos militares con que se cuenta. Junto a estos desplazamientos, hay otro tipo de "huidas": algunos partidarios se ausentan por largas temporadas a sus tierras y chacras para ver sus ganados, ${ }^{25} \mathrm{y}$ otros se aprovechan de la licencias que se expiden por razones de enfermedad, para terminar desertando del servicio definitivamente. Incluso se registra una fuga amorosa de un fuerte a otro, la del soldado Carlos Tolava, del fuerte de Centa, que huye a Ledesma con una mujer llamada Rufina, porque la familia de ella y los curas del fuerte y la reducción no consienten su matrimonio. El comandante de Ledesma pedirá instrucciones para saber qué hacer con estos amantes, obteniendo el consentimiento para que puedan quedarse en Ledesma a servir como soldado y en matrimonio con su amante.

En cuanto a la condición social de los soldados, pueden distinguirse distintos grupos: uno integrado por mestizos, pardos y españoles pobres que probablemente hayan residido en el "monte", dedicándose a la cría de vacas y mulas en los alrededores de la frontera y al abigeato en las haciendas y sobre las arrias que recorren la región. Su conchabo como soldados no significa que descuidan sus medios de reproducción social. Ocasionalmente, y sin prestar demasiada atención a las rigideces de la vida militar, regresan a sus chacras a cuidar sus ganados y atender sus familias que al parecer no siempre se trasladan con ellos al fuerte.

Otro grupo de soldados partidarios lo forman individuos de la ciudad de Jujuy que voluntariamente se ofrecen a las autoridades de la frontera para cubrir las plazas de soldados que quedan vacantes. En Ledesma y en

25 ATJ, Juicio por muerte de Cristobal Mascareño en Tilquiza por Dionicio Flores, Jujuy, $1750,34,1152$. 
los otros fuertes de la frontera las vacantes son numerosas, las que no se deben tanto a las deserciones o muertes, que suman cuatro y veintiuno, respectivamente entre 1780-1790, sino por la gran cantidad de soldados, sargentos, capitanes o comandantes de fuertes que en el medio del servicio contratado se "borran" de él, es decir que se retiran a sus chacras o haciendas, o regresan a las ciudades de Jujuy y Salta de donde habían venido, comunicando su decisión unos meses después. Esta nueva categoría de soldado presidiario, la de "borrado", es notablemente significativa en el número de bajas que sufre esta frontera, ya que para el período de 1781-1790 los "borrados" superan ampliamente a los desertores y muertos, sumando 116 hombres. ${ }^{26}$

Estos individuos que se contratan en la ciudad, suelen pertenecer a la casa familiar del comandante general de la frontera, y otros son forasteros de las jurisdicciones vecinas que vienen en busca de mejores oportunidades sociales y económicas, que no son escasas, ya que en estos fuertes los soldados, cabos o sargentos cobran 90 pesos al año, más ración de carne, bizcocho, tabaco y un uniforme. Siendo otra razón que justifica el enrolamiento, la posibilidad de insertarse como productor o comerciante en el mercado de grandes distancias y de diversas mercancías que se esta desarrollando por estos años, ya que asentados en la frontera, se pueden dedicar a abastecer de caballadas a los fuertes, a traficar herramientas, aguardiente, telas, botas de mula y hasta coches de paseo, para las haciendas o reducciones. ${ }^{27}$ Utilizando la importante cantidad de efectivo que reciben de los espaciados pagos, como sucede en 1790 cuando los soldados y oficiales de Ledesma reciben el pago atrasado de tres años de servicio: en ese momento, el comandante Sevilla tiene 1.800 pesos en efectivo, su segundo Lorenzo Revuelta 390, el teniente Francisco Javier Robles 600, igual que el capellán Policarpio Villalobos, mientras el alférez, los cuatro cabos y los 22 soldados, tienen en sus manos 288 pesos. Sin embargo en este territorio que en este momento se presenta como pleno de oportunidades, también hay muchos sacrificios que sobrellevar. De ello resulta que la habilitación al ascenso social en esta frontera no es para todos, como es el caso del "soldado Rivas un manchego a quien vuestra merced dio plaza... por europeo y por consiguiente caballero, todo lo incomoda, todos los días esta solicitando irse que el no puede sobrellevar esto. Que no es extraño no pueda un señor europeo tolerar tales fati-

26 AHJ, ARR, Lista general de la tropa partidaria.... 436 y 438.

27 AHJ, ARR, Correspondencia entre Carlos Sevilla y Gregorio de Zegada, Jujuy, 1780-1800, 
gas, con que verá y me dirá si podremos enviarle con mil rábanos porque se puede dar dinero encima por su ausencia".

El trabajo bajo un sol abrasador, las fiebres palúdicas, las frías mañanas sin una taza de chocolate y el tiempo que no pasa porque no se tiene ni siquiera un almanaque que marque el cronograma de servicio, dan lugar a que el dicho manchego regrese finalmente a la ciudad de Jujuy por razones de "enfermedad". Pérdida que el comandante del fuerte no sólo no lamenta, sino que le va a pedir a su superior Gregorio de Zegada que por más que se cure no lo mande de nuevo. ${ }^{28} \mathrm{El}$ espacio fronterizo no parece haber albergado a muchas familias de estos soldados, pese a las recomendaciones de las autoridades sobre preferir el alistamiento de partidarios que tengan familia, premiándolos por ello con doble ración de carne, propuesta que también aparece en los proyectos ilustrados de Félix de Azara, de 1799, donde se indica que la tropa debía ser casada y reclutada en las provincias vecinas por un salario de 30 pesos. ${ }^{29}$

En Ledesma la mayoría de los soldados viven solos, tal vez porque sus esposas e hijos quedaban al cuidado de las chacras y ganado o por las numerosas enfermedades que había en la región. Así por ejemplo el año 1792 parece haber sido especialmente duro en las fiebres palúdicas llamadas "chucho". En marzo el comandante informa a sus superiores que no hay forma para que la población se "aparte" del chucho, luego el 24 de setiembre una tal Juanita está grave de la misma enfermedad, y el 12 de diciembre notifica de la muerte de María Palacios dejando una "hijita sarnosa que no tiene cura, ni crece y es medio sonsadilla cuya carga será muy a disgusto para cualesquiera". ${ }^{30}$

Respecto de las conductas sociales de los soldados partidarios, el comandante del fuerte de Ledesma resalta la poca confianza que les tiene, algo que no resulta extraño, pues los soldados suelen mentirle y engañarlo cuando piden traslados a otros fuertes y a mitad de camino se fugan a la ciudad de Jujuy. Otros abusan de los permisos por enfermedad para irse varios meses a sus chacras; incluso algunos aprovechan las comisiones de servicio que los llevan hasta Salta o Jujuy para tomarse varios días de des450 y 430.

28 AHJ, ARR, Correspondencia entre Carlos Sevilla y Gregorio de Zegada, Jujuy, 1780-1800,

29 Azara, Felix, Informes sobre varios proyectos de colonizar el Chaco, En Angelis, Pedro de, Entradas al Chaco, Colección de obras y documentos relativos a la historia antigua y moderna de las provincias del Río de la Plata, Jujuy, 1989, pág. 18.

30 AHJ, ARR, Correspondencia entre Carlos Sevilla y Gregorio de Zegada, Jujuy, 1780-1800, 430,435 y 439 . 
canso o para robar en las haciendas y casas particulares de los alrededores. Por ello, cuando el comandante de Ledesma debe ordenar alguna comisión de servicio lejos del fuerte, en una reducción por ejemplo, lo piensa muy detenidamente. Así sucede en 1792 cuando el cura de San Ignacio debe pedirle varias veces que le envíe cuatro soldados para protegerlo de las actitudes rebeldes de los indios. Sólo accederá a enviarlos cuando reciba una orden directa de su superior Gregorio de Zegada, comisionando a cuatro hombres de notable "honradez y desempeño", que puedan ejecutar el auxilio sin caer en los inconvenientes que suceden cuando los soldados van a las rancherías de los indios.

Junto a este grupo heterogéneo de individuos, actúan como soldados partidarios los indígenas reducidos en las rancherías del fuerte. Ledesma estuvo asistido a comienzos de siglo XVIII por los indios ojotaes, reducidos en el pueblo de San Antonio de Ledesma con ese fin. Por ese servicio, el gobernador Esteban de Urízar y Arespacochaga los exime de pagar "la tasa ni tributo...ni contribuir con indios a las mita a las ciudades, por ser presidiarios... obligados a defender la frontera y salir de campaña". ${ }^{31}$ A fines de siglo parecen haber desaparecido del servicio del fuerte ya que no se los menciona en ningún informe. En su reemplazo wichíes reducidos en el fuerte con sus familias sirven como soldados. Trabajan en los rastrojos y acequias de sus tierras y en las haciendas, ${ }^{32}$ pero parecen haber sido utilizados especialmente como mediadores entre las demandas de trabajo de los hacendados y los curas de San Ignacio y de Centa, y los tobas y wichíes que estacionalmente "salen" de adentro del Chaco para trabajar en dichas unidades productivas. Su rol resulta fundamental para persuadir y hacer retornar a otros aborígenes reducidos que se fugan a mitad de zafra, o cuando hay que convencer a los no reducidos de los beneficios que acarrea una entrada pacífica de conchabo en las haciendas, en vez de una violenta de robo de ganado. ${ }^{33}$

En el desarrollo de esta función, las autoridades confían en las relaciones de parentesco y en los sistemas de autoridad prehispánicos. Por ello se envían al frente de estas partidas de indios a los hijos de los caciques, acompañados por los alcaldes y un lenguaraz. Una segunda instancia de mediación (o que se hace conjuntamente a la primera) es enviar a las espo-

31 Lozano, Pedro, Descripción Corográfica...., pág. 384. 1800,440 .

32 AHJ, ARR, Correspondencia entre Carlos Sevilla y Gregorio de Zegada, Jujuy, 1780$1800,442$.

33 AHJ, ARR, Correspondencia entre Carlos Sevilla y Gregorio de Zegada, Jujuy, 1780- 
sas o mujeres parientes de los fugados, sobrinas o cuñadas, armadas únicamente de galleta, charque y tabaco. Como agentes de la nueva autoridad en la región, estos indios son equipados no con armas, sino con comida y regalos para que "congratulen" a los otros. El comandante del fuerte los habilita con caballadas para seguirlos, carne de vaca, bizcocho, sal y mazos de tabaco, para que la intimación surta más efecto. Llevan además, como representantes de la corona, el discurso de sometimiento colonizador: "Van enteradas del benigno perdón de vuestra majestad e volviéndose pacíficamente a su reducción para trabajar, y del rigor con que serán tratados de no hacerlo asî́". ${ }^{34}$

Este rol de algunos indígenas reducidos en el fuerte provoca resquicios en sus relaciones intraétnicas. Los caciques pierden autoridad frente a competidores que esgrimen una legitimidad distinta a la propuesta por los españoles con sus títulos de corregidor, alcalde, madrinero y lenguaraz. Basada en los sistemas de parentesco y el liderazgo para encabezar la recolección de miel y algarroba para las celebraciones tradicionales, estos nuevos líderes logran encabezar permanentes fugas del servicio en el fuerte y en las reducciones.

Por otro lado los indígenas que sirven como auxiliares en el reclutamiento de mano de obra aborigen, son identificados como tales y por lo tanto su rol mediador se debilita. Esto puede verse en la negativa que esgrime un grupo de indígenas a integrar una partida que se prepara para capturar un grupo importante de fugados de San Ignacio: dicen que no serán bien recibidos por Trejo, líder de los fugados, ni por los otros indios porque "como ellos el día que se fueron en su seguimiento habían ido como soldados ...estarían enojados con ellos, y podrían recelar iban a engañarlos y los atacarían". ${ }^{35}$

\section{Las autoridades fronterizas y sus temores}

La frontera chaquense de Jujuy es guardada por el capitán de infantería Carlos Sevilla, máxima autoridad como comandante de fronteras con jurisdicción sobre los fuertes de Ledesma, Santa Bárbara y San Bernardo. En 1781 llega a la región al mando del batallón de Saboya, para contribuir $1800,445$.

34 AHJ, ARR, Correspondencia entre Carlos Sevilla y Gregorio de Zegada, Jujuy, 17801800,475 .

35 AHJ, ARR, Correspondencia entre Carlos Sevilla y Gregorio de Zegada, Jujuy, 1780- 
al control de los tobas rebeldes de San Ignacio que habiéndose fugado de ella, asaltaron el fuerte de Ledesma poniendo en peligro toda la frontera, brindando una oportunidad para que los vagabundos, apóstatas y forajidos de los alrededores de la ciudad se levantaran contra las autoridades. Su llegada al frente del batallón de Saboya contribuye a la exitosa defensa de la ciudad de Jujuy y a la recuperación del control sobre los fuertes, reducciones y caminos de la frontera, una tarea que comparte con el gobernador de armas Gregorio de Zegada, comerciante y hacendado con importantes mercedes de tierras en la zona.

Si bien en la "reconquista" de esta porción del Chaco participa toda la ciudad de Jujuy, con el auxilio de la de Salta y del citado batallón de Saboya, es el comandante de Carlos Sevilla, el coronel Gregorio de Zegada, quien obtiene los mayores réditos, pues además de nuevas mercedes de tierras en el Chaco, recibe un importante respaldo del rey que lo declara comandante de la frontera de Jujuy y coronel de milicias de la frontera ${ }^{36}$ Mientras tanto, luego de su participación en la represión de los alzados contra la corona, Carlos Sevilla pasa a la ciudad de Salta donde se casa con una de sus vecinas, para retorna a Jujuy el 19 de octubre de 1785 cuando asume el comando de la frontera Jujeña del Chaco desde el fuerte principal de Río Negro, quedando también bajo su jurisdicción Ledesma, Santa Bárbara y San Bernardo.

En este servicio recibe el 20 de diciembre de 1787 de los administradores particulares del ramo de sisa de la ciudad de Jujuy, el dinero en efectivo "tabla y mano propia", para el pago de sueldos de la tropa partidaria, tarea que realiza en presencia de Zegada. A fines de 1789 pero esta vez en Ledesma como sede de la comandancia, alista a la tropa partidaria de toda la frontera y realiza el pago de tres años de servicio bajo la supervisión del gobernador intendente Andrés Mestre. Si el traslado de la comandancia de la frontera desde Río Negro a Ledesma se vincula con un cambio político hacia esta porción del Chaco (de la cual son exponentes la fundación de la ciudad de Orán y la reducción de Centa) el reemplazo del comandante general de armas de Jujuy por el gobernador intendente, como autoridad que supervisa el pago de la tropa partidaria, indica la llegada de las reformas borbónicas a la frontera.

36 AHJ, ARR, Libro copiador de cabildo, Jujuy, 1782, 28, págs. 276-277. Paralelamente a su ascenso político Gregorio de Zegada triunfaría económicamente. Desde una concepción ilustrada será uno de los primeros hacendados en introducir la elaboración de azúcar y aguardiente en la región con maquinarias y utilizando mano de obra esclava y libre. 
Subordinada al capitán Sevilla tenemos una variada oficialidad, compuesta por un segundo, el sargento Lorenzo Revuelta (que se ha desempeñado como capitán del fuerte entre 1781 y 1789), un teniente llamado Francisco Valdés, un capitán don Policarpo Villalobos y el alférez Pedro Arias, todos ellos españoles. A ellos deben sumárseles cuatro cabos, un armero y 22 soldados probablemente mestizos, equipados con fusiles con bayoneta, lanzas y dos cañones. En las relaciones sociales entre el cuerpo de soldados y oficiales puede apreciarse que Sevilla confía únicamente en su segundo Lorenzo Revuelta y sus tenientes, pues considera que sus soldados se prestan fácilmente a todo tipo de "bajezas" en las rancherías de los indios y están pendientes de cualquier oportunidad para evadir el servicio militar y laboral, fugándose o borrándose cuando los manda a cumplir comisiones en la ciudad o en otros fuertes. ${ }^{37}$

Tras siete años de servicio en la frontera, Sevilla decide en 1792 trasladar a su familia desde la ciudad de Salta para que viva junto a él en Ledesma. ${ }^{38}$ Esta decisión muestra el nuevo carácter de la frontera que comienza a poblarse de familias y a despoblarse de presidiarios, y que va dando lugar a haciendas en reemplazo de los fuertes. Por otro lado el comandante del fuerte trabajará como un afanoso colonizador en las tierras que rodean al mismo, donde invierte todo su salario para comprar semillas, construir las acequias para los sembradíos, desmontar el terreno y contratar herreros que construyan los alambiques necesarios para producir aguardiente, hasta llegar a endeudarse para comprar las herramientas para el rastrojo y la cosecha.

Esta actitud también perfila el cambio en la política hacia la frontera del Chaco. Sevilla parece preocuparse más en solicitar herreros que compongan las herramientas para labrar, que armeros que arreglen las numerosas armas descompuestas. En la misma línea de pensamiento solicita reiteradamente a sus superiores que le manden azadas, hoces y palas, alambiques y toneles para el aguardiente en vez de cañones, sables o fusiles.

Sin embargo, este rol de colonizador no le hace descuidar completamente sus obligaciones de jefe militar. Informa cada semestre de la distribución de las raciones entre los partidarios y del estado de las armas, ${ }^{39}$ enro-

37 AHJ, ARR, Correspondencia entre Carlos Sevilla y Gregorio de Zegada, Jujuy, 1780$1800,452$.

38 AHJ, ARR, Correspondencia entre Carlos Sevilla y Gregorio de Zegada, Jujuy, 17801800, 469.

39 AHJ, ARR, Correspondencia entre Carlos Sevilla y Gregorio de Zegada, Jujuy, 1780$1800,433$. 
la a los soldados partidarios con el tiempo del servicio de cada uno para su pago, y supervisa el trabajo de los curas de las reducciones de San Ignacio y Centa: luego de posicionarlos en el cargo y registrar su fecha de asunción para el pago del sínodo, les impone sobre las costumbres que deben guardarse en el trato con indios, habituados a las dádivas y regalos más que a las ceremonias y liturgias descarnadas y sin galleta, aspectos que si no se tienen en cuenta pueden derivar en alzamientos y fugas numerosas hasta llegar a despoblar la reducción. ${ }^{40}$

Junto a estas tareas, deben coordinar el auxilio que los hacendados prestan para reducir a los indios fugados del fuerte, reducciones o haciendas y dispone la realización de campañas para amedrentar a los indígenas que osan asaltar las haciendas. Por el conjunto de tareas que realiza, goza de cierta libertad para disponer sobre las vacantes que se producen en el servicio de la frontera, enviando los listados de los puestos libres con propuestas de soldados con nombre y apellido. ${ }^{41}$

Finalmente, como parte de su responsabilidad de comandante de la frontera, también cuida los intereses en la región de su superior el capitán de armas y teniente de gobernador de la ciudad de Jujuy, el coronel Gregorio de Zegada. Así manda soldados a su hacienda para construirle potrerillos para que sus mulas inviernen, hace reparar sus acequias o manda a indios a que limpien los rastrojos de las plantaciones de caña de azúcar, dejándolos bajo el mando del mayordomo de la hacienda. Pero lo más importante es el auxilio que sus tropas prestan al mayordomo de Zegada, Miguel Antonio de Iturbe para realizar y proteger el traslado de ganado, aguardiente y azúcar que desde la hacienda de San Lorenzo remite constantemente a las ciudades de San Salvador de Jujuy y Salta. ${ }^{42}$

\section{Los comerciantes de la frontera}

El comisario y prefecto de las misiones de Tarija fray Antonio de Comajuncosa en su visita de 1800 destaca que en esta porción del Chaco

40 AHJ, ARR, Correspondencia entre Carlos Sevilla y Gregorio de Zegada, Jujuy, 1780$1800,431,448$ y 486.

41 AHJ, ARR, Correspondencia entre Carlos Sevilla y Gregorio de Zegada, Jujuy, 17801800, 366 .

42 AHJ, ARR, Correspondencia entre Carlos Sevilla y Gregorio de Zegada, Jujuy, 17801800,480 . 
"Suelen ir a las misiones varios comerciantes del Valle Grande, de la Laguna, de Tarija y de otras partes, con géneros útiles, y a éstos se les recibe con mucho agrado, y se hacen con ellos los trueques ya mencionados... de Santa Cruz van otros con tasajos de carne chasqueada, melados, alfeñiques y otros frioleras para trocar por algodón e hilados, y cuando esto sobra se les da permiso a los indios, pero cuando escasean se les niega por no dejar a los indios desnudos" ${ }^{43}$ La introducción de estos productos debe ir con licencia y guía extendidas por el gobierno de Santa Cruz, so pena de decomiso; y se prohibe especialmente el tráfico del aguardiente en las misiones. ${ }^{44}$

El mercado de estos comerciantes son las reducciones, las rancherías de los fuertes y las haciendas azucareras de la región. En este tráfico los fuertes son imprescindibles, porque se prohibe a los traficantes o sus productos residan o pasen en los pueblos de indios de las reducciones. De esta forma las barracas de Ledesma sirven como depósitos para las mercaderías y albergan a los comerciantes y sus auxiliares, que se sostienen con las raciones y vestimentas que allí se les reparten, arreglando las cuentas con los comandantes o con sus superiores a su regreso a la ciudad.

Como en esta frontera los comerciantes cumplen una función esencial para el sostén de la población española, aunque deban pagar por el depósito de la mercadería que guardan en los fuertes, saben que pueden contar con el auxilio de sus vituallas para el tráfico mercantil, pues como sucede en las reducciones, siempre habrá algo de la carne obtenida de sus estancias "para los forasteros, a quienes se suele socorrer, particularmente a los comerciantes". ${ }^{45}$ Por otro lado las autoridades de la frontera le exigen a los comerciantes llevar la correspondencia oficial, algunos productos, como palmas, y hasta dinero.

Finalmente no hay demasiadas precisiones en cuanto a su origen: sólo se menciona varias veces a un tal "Paraguay", como comerciante que trafica con géneros y ganado, y que parece ser persona de cierta confianza del comandante de Ledesma, pues le encarga la comisión de llevarle dinero a su superior el coronel Gregorio de Zegada y comprarle distintos artículos de labranza en la ciudad de Salta. ${ }^{46}$

43 Tamajuncosa, Antonio, Descripción de las misiones al cargo del colegio de Nuestra Señora de los Angeles de la Villa de Tarija. En Angelis, Pedro de (1910) Entradas al Chaco, Colección de obras y documentos relativos a la historia antigua y moderna de las provincias del Río de la Plata, Jujuy, 1989, pág. 219.

44 Ibídem, pág. 220.

45 Ibídem, pág. 218. 436 y 438 .

46 AHJ, ARR, Correspondencia entre Carlos Sevilla y Gregorio de Zegada, Jujuy, 1780-1800, 


\section{Los indígenas chaquenses: entre el servicio y la fuga}

Dentro del radio de Ledesma se ubican dos reducciones: San Ignacio y Nuestra Señora de las Angustias de Centa, de indios tobas y wichíes respectivamente. Además de estos grupos hay abipones y chiriguanos, que aunque se encuentran más hacia el este de las reducciones antedichas, mantienen cierta presión en el control de los recursos sobre los anteriores indígenas.

Esta población indígena chaquense entabla múltiples relaciones con Ledesma. Los indígenas reducidos allí son wichíes que absorbieron a los ojotaes y ocloyas que antes servían al fuerte como soldados o esclavos, y en este momento mantienen constantes relaciones con los tobas reducidos en San Ignacio y con los wichíes reducidos en Centa, además de salir a mielar con grupos que no están reducidos ni en las misiones ni en los fuertes, pero que "salen" periódicamente de "tierras adentro" a trabajar en las haciendas o en las tierras de los fuertes.

Esta conducta es ambivalente ya que puede variar rápidamente a un ataque contra los ganados de las haciendas: así lo hace el cacique wichíes llamado "Lunes" que alberga a un importante grupo toba fugados de San Ignacio y por ello es compelido por las autoridades a que defina su actitud pues "que motivo tiene para querer incomodarnos cuando las veces que ha salido con su gente ha sido bien tratado que han trabajado y pagados se han vuelto, sin que se les ocasione perjuicio alguno, que sigan en la misma amistad y salga pacíficamente a trabajar cuando quiera o que de no, no se llegue a estas inmediaciones porque será tratado como enemigo". ${ }^{47}$

Otro aspecto interesante es que no surgen con claridad conflictos interétnicos ni tampoco la dicotomía que se supone entre pueblos "de a pie" más dóciles y los de "tierra adentro" más guerreros; ${ }^{48}$ ya que muchas veces los tobas de San Ignacio huyen para recoger algarrobas o miel, y lo hacen junto con wichíes del fuerte de Ledesma, reuniéndose todos en las tolderías de otros wichíes no reducidos para celebrar las tradicionales libaciones con algarroba y miel. ${ }^{49}$

Donde si hay rivalidades es con los chiriguanos, lenguas y guaycurúes, que se aprovechan de quienes huyen de las reducciones para robar-

47 AHJ, ARR, Correspondencia entre Carlos Sevilla y Gregorio de Zegada, Jujuy, 17801800, 473.

48 Vitar, Beatriz, Guerra y misiones...., pág. 23.

49 AHJ, ARR, Correspondencia entre Carlos Sevilla y Gregorio de Zegada, Jujuy, 1780-1800, 445,440 y 442. 
les mujeres y ganados. Así se aprecia como las rivalidades interétnicas se mezclan con el proceso reduccional en fuertes, haciendas y misiones complementando las anteriores diferencias étnicas por una determinada por la conquista: reducidos contra no reducidos; diferencias o rivalidades que se superan en momentos de penuria, hambruna o sobrexplotación de los hacendados.

Un tercer aspecto de estos grupos chaquenses tiene que ver con las razones que llevan a los reducidos a fugarse de las reducciones, haciendas o fuertes. Los indios que se fugan de Ledesma y de San Ignacio declaran que suelen hacerlo para ir a recolectar miel y que ya en el monte son "llevados" por otro grupo no reducido a mielar y comer algarroba; que esto es lo único que pretenden hacer con su huida y que piensan volver luego al servicio del fuerte o de la reducción..$^{50}$

El comandante de Ledesma entiende la importancia de esta actividad para los chaquenses, al punto de recomendar al mayordomo de la hacienda de San Lorenzo, Antonio de Iturbe que libere a los wichíes ocupados en los rastrojos en las épocas y horarios de los rigurosos calores, porque son aquellas épocas cuando realizan sus "borracheras", es decir sus juntas de canto, baile y bebida, ${ }^{51}$ sabiendo que pasada la "algarroba" los indígenas trabajadores "caerían" solos en busca del trabajo..$^{52}$

Otra causa de la fuga de indígenas reducidos es el maltrato al que los someten los mayordomos de los hacendados. En las cercanías de Ledesma están las tierras de San Lorenzo, propiedad de Gregorio de Zegada, administrada por su sobrino Miguel Antonio de Iturbe quien a pesar de la dependencia jerárquica que el comandante del fuerte tiene respecto de su tío, no acuerda muchas veces con Sevilla, especialmente en el tema del trato de los indígenas trabajadores.

Mientras que el comandante aconseja respetar sus horarios de trabajo y sus épocas de recolección de algarroba o meleo, Iturbe no está de acuerdo y prefiere azotar a los indios que abandonan el servicio de la hacienda. Ante esta situación, Sevilla comunica a las autoridades que este trato a los indígenas puede originar un estallido de "revoluciones" y que se llegue a "incendiar" el Chaco con el alzamiento en armas de los indios, además de $1800,454$.

50 AHJ, ARR, Correspondencia entre Carlos Sevilla y Gregorio de Zegada, Jujuy, 1780-

51 Santamaría, Daniel, "Población y economía interna...., pág. 183. $1800,437$.

52 AHJ, ARR, Correspondencia entre Carlos Sevilla y Gregorio de Zegada, Jujuy, 1780- 
producirse perjudiciales fugas para el trabajo de la zafra, desligándose de toda responsabilidad si esto llegara a suceder.

Sin embargo en otra correspondencia que mantiene Gregorio de Zegada con su mayordomo, se ve que su actitud intolerante hacia la mano de obra aborigen responde a las complejas relaciones que los indígenas tienen en la hacienda con sus patrones, capataces o mayordomos. Allí los patrones se ven obligados a mostrar cierto desprendimiento al contratar trabajadores indígenas ofreciéndoles carne y tabaco, además del pago estipulado que a veces se hace en plata, para que los indios, "vayan contentos con todo lo que les diste y digan a los otros que todo está bien". También les cede tierras cercanas a la hacienda, dándoles semillas y bueyes para cultivar sus zapallos..$^{53}$ Esta generosidad puede a veces resultar contraproducente porque los indios salen a trabajar a las haciendas en un número mayor al que se necesita, trayendo con ellos a su "chusma" para comer y no hacer casi nada, según palabras del hacendado. ${ }^{54}$ Finalmente ante estos fracasos en la coacción laboral ejercida sobre la mano de obra indígena, lo único que atina a aconsejarle el propietario a su mayordomo es que si se fugan a mitad de trabajo con la plata que se les anticipó, tenga "paciencia, pues que no hay otro arbitrio". ${ }^{55}$

Sin poder precisar si los azotes que Iturbe les da a los indios es una práctica constante, o un exceso que hasta el comandante condena, estos documentos aportan datos para ampliar la mirada sobre las respuestas y los métodos de la coacción laboral ejercida sobre los indígenas chaquenses, en unas relaciones laborales peculiares y típicas de una economía mercantilista. Por último, otro motivo que puede llevar a la fuga de los chaquenses de las reducciones, está en las complejas relaciones que mantienen con sus padres doctrineros, antes jesuitas y ahora franciscanos.

En el año 1793 dieciséis hombres adultos con sus familias y diez muchachos grandes se fugan de la reducción de San Ignacio porque no quieren al padre franciscano Godoy, sino a otro cura, pidiendo que regrese el padre fray Eusebio Victoria, anterior cura de la reducción, que había sido trasladado a la ciudad de Córdoba. ${ }^{56}$

Si bien los wichíes no detallan el porqué de su disgusto con Godoy, el comandante del fuerte si precisa cuales pueden haber sido las causas del

53 AOJ, Papeles de la familia Iturbe, Jujuy-Ledesma, 1790, 18, 176.

54 AOJ, Papeles de la familia Iturbe, Jujuy-Ledesma, 1790, 18, 188.

55 AOJ, Papeles de la familia Iturbe, Jujuy-Ledesma, 1790, 18, 255. $1800,453$.

56 AHJ, ARR, Correspondencia entre Carlos Sevilla y Gregorio de Zegada, Jujuy, 1780- 
malestar de los indios. Dice que el cura le solicitó un envío de soldados para resguardar su persona y entablar un mejor orden entre los indios. No se hizo lugar porque estos indios nunca habían faltado a la obediencia y respeto de su cura, y que a su parecer el verdadero auxilio que se le pudiera dar al padre sería darles de comer a su "gente", pues "nada los tendría más a raya". ${ }^{77}$

Más adelante el comandante pone sobre aviso a las autoridades superiores sobre las causas del malestar indígena, al denunciar que el cura atiende inadecuadamente a sus indígenas reducidos tratándolos con una "fatal nulidad, impropios modos de hablar, irregular trato a los indios, castigando por sí con el sablecito, haciéndose el guapito". ${ }^{58}$ Lo que provocará una violenta reacción del propio cacique de la reducción, Pedro Xuárez, que imprecara al cura atropellando la puerta de la iglesia y entrando al sagrario con el sombrero puesto y un cuchillo en una mano, sin llegar a mayores actos, pero finalizando su protesta al día siguiente con un ataque directo al cura que consistió en ponerle una mano en el pecho y amenazarlo con un palo "sin acción alguna pero encarándoselo y altanareado". ${ }^{59}$ Por estos actos, Xuárez es apresado y se le substanciará un juicio sumario, enviándolo con prisiones a la ciudad de Salta. Mientras tanto, los indios de la reducción se fugan masivamente, y el cura "guapito" huye a la protección del fuerte. Finalmente el episodio se resuelve cuando una partida de indios busca a los fugados con charque y tabaco, y con la noticia de que el cura golpeador ha sido sacado de la reducción. ${ }^{60}$

\section{La nueva sociedad de frontera}

Si hasta la segunda mitad del XVIII los vecinos desheredados del sistema de encomiendas buscan en la guerra un medio de promoción social y el espacio social más adecuado para ello es la frontera presidiaria del Chaco, a finales del siglo las políticas colonizadoras y las adaptaciones de los indígenas chaquenses perfilan otro tipo de frontera. $1800,441$.

57 AHJ, ARR, Correspondencia entre Carlos Sevilla y Gregorio de Zegada, Jujuy, 17801800,431

58 AHJ, ARR, Correspondencia entre Carlos Sevilla y Gregorio de Zegada, Jujuy, 1780-

59 AHJ, ARR, Correspondencia entre Carlos Sevilla y Gregorio de Zegada, Jujuy, 1780$1800,449$.

60 AHJ, ARR, Correspondencia entre Carlos Sevilla y Gregorio de Zegada, Jujuy, 1780$1800,454$. 
$\mathrm{Al}$ parecer ésta sigue siendo un espacio peligroso. Robos de ganado de las haciendas y la muerte de algún trabajador mestizo y hasta de hacendados, aparecen siempre en los informes de los misioneros de finales de siglo, por lo que también continúan las expediciones punitivas de escarmiento, pero con el objetivo principal de buscar a los fugados del sistema reduccional franciscano y de los fuertes. Junto a esto también comienza a perfilarse en los distintos grupos sociales y en las autoridades una visión distinta. Como lo expresa el comandante del fuerte de Ledesma: "Esta bien la demasiada contemplación, pero ni tampoco el rigor del fuego, por no incendiar el sosegado chaco". En una actitud de cautela que muestra que las autoridades perciben que la acción militar limita el desarrollo colonizador, renegando junto al vecindario de los hacendados sobre lo extenuante de las campañas punitivas, en cuyo ínterin se les destruye la hacienda, malogran su trabajo y les falta el sustento para sus familias.

Respecto de los indígenas, según el comandante de Ledesma parecen no darse cuenta de la fragilidad del asentamiento hispánico en la región, "la frontera está sosegada sólo en apariencia... si ellos se hicieran la reflexión de que no tenemos gente para nada más que guardar mal la casa, que harían?" ${ }^{61}$ Esta falta de percepción de los chaquenses reducidos en reducciones y fuertes, de los fugados, los convertidos a medias y los no reducidos que bajan a servir las haciendas, obedecería a motivos más concretos que a una disminución del "ethos guerrero", ya que siempre que el comandante informa sobre el regreso de indios fugados, se describe un triste paisaje de hambre y necesidad: "traspillados de hambre, vienen desnudos y muy enfermos, dejando dos indios muertos y dos chinas y algunas cosas. Quedan seis viniendo por demasiado débiles y no han podido seguir". ${ }^{62} \mathrm{Y}$ cuando se produce la llegada de indios para trabajar en la zafra del fuerte o de las haciendas, las autoridades mencionan las mismas razones: búsqueda de trabajo y alimentos.

También los indígenas expresan los mismos motivos, como lo hace un grupo de veinte indios wichíes, con siete muchachos y cuarenta mujeres y chiquillos con ovejas y algunos ladinos, que dicen venir al fuerte para conchabarse, trabajar, comer y vestirse, sin ninguna otra "idea" que vienen sin armas y en paz, y según el comandante ésta parece ser su intención pues se

61 AHJ, ARR, Correspondencia entre Carlos Sevilla y Gregorio de Zegada, Jujuy, 1780$1800,431$.

62 AHJ, ARR, Correspondencia entre Carlos Sevilla y Gregorio de Zegada, Jujuy, 1780$1800,473$. 
trata de gente robusta que podrían ganar la comida para su familia y alguna vestimenta y los muchachos y mujeres podrían dedicarse a construir capachos, una especie de recipiente cóncavo de palma con dos asas. ${ }^{63}$

Eterno retorno de los fugados al sistema reduccional de los fuertes, misiones y haciendas, que se da en "cueros" y perseguidos por el hambre. De esta manera, descartada la guerra como solución de sus necesidades, queda como una letanía el testimonio de un líder toba que comanda un grupo de indios fugados, que finalmente debe retornar al control social de la reducción, militar del fuerte y laboral de las haciendas: "que había dicho Antonio Tabarcachi, el sacristán, no querían volver sino irse a su tierra que tantas veces se habían ido y los habían vuelto, pero que ahora no habría de ser asî́". ${ }^{64}$

63 AHJ, ARR, Correspondencia entre Carlos Sevilla y Gregorio de Zegada, Jujuy, 17801800,361 .

64 AHJ, ARR, Correspondencia entre Carlos Sevilla y Gregorio de Zegada, Jujuy, 1780$1800,453$. 